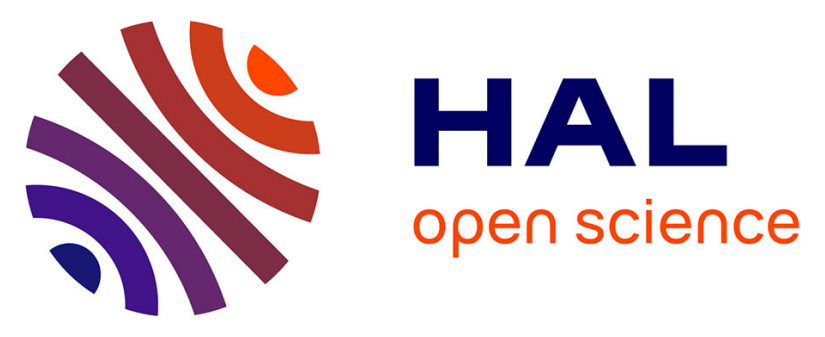

\title{
Study of the Effect of Substituents of ortho-Phenylenediamines in the Opening of Lactones and Lactams for Access to Benzimidazol-2-yl Alkanols and Benzimidazol-2-yl Alkylamines
}

Omar Castillo-Aguilera, Patrick Depreux, Alexia Ballée, Florian Beaurain, Paola B Arimondo, Laurence Goossens

\section{To cite this version:}

Omar Castillo-Aguilera, Patrick Depreux, Alexia Ballée, Florian Beaurain, Paola B Arimondo, et al.. Study of the Effect of Substituents of ortho-Phenylenediamines in the Opening of Lactones and Lactams for Access to Benzimidazol-2-yl Alkanols and Benzimidazol-2-yl Alkylamines. SYNLETT, 2020, 31 (12), pp.1216-1220. 10.1055/s-0040-1707112 . pasteur-03026011

HAL Id: pasteur-03026011

https://hal-pasteur.archives-ouvertes.fr/pasteur-03026011

Submitted on 15 Dec 2020

HAL is a multi-disciplinary open access archive for the deposit and dissemination of scientific research documents, whether they are published or not. The documents may come from teaching and research institutions in France or abroad, or from public or private research centers.
L'archive ouverte pluridisciplinaire HAL, est destinée au dépôt et à la diffusion de documents scientifiques de niveau recherche, publiés ou non, émanant des établissements d'enseignement et de recherche français ou étrangers, des laboratoires publics ou privés. 


\section{Study of the Effect of Substituents of ortho-Phenylenediamines in the Opening of Lactones and Lactams for Access to Benzimidazol- 2-yl Alkanols and Benzimidazol-2-yl Alkylamines}

\author{
Omar Castillo-Aguilera ${ }^{a, b}$ \\ Patrick Depreux ${ }^{\mathrm{a}, \mathrm{b}}$ \\ Alexia Ballée $e^{a, b}$ \\ Florian Beaurain ${ }^{\mathrm{a}, \mathrm{b}}$ \\ Paola B. Arimondoc \\ Laurence Goossens*a,b \\ a Univ. Lille, CHU Lille, ULR 7365 - GRITA - Groupe de Recherche \\ sur les formes Injectables et les Technologies Associées, 3 rue \\ du Pr. Laguesse, 59000 Lille, France \\ laurence.goossens@univ-lille.fr \\ b Institut de Chimie Pharmaceutique Albert Lespagnol, 3 rue du \\ Pr. Laguesse, 59000 Lille, France \\ ' Epigenetic Chemical Biology, Department of Structural Biology \\ and Chemistry, Institut Pasteur, UMR3523 CNRS, 75015 Paris, \\ France
}
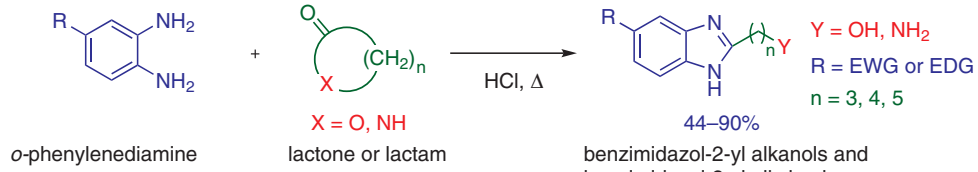

benzimidazol-2-yl alkanols and benzimidazol-2-yl alkylamines 18 examples
Received: 01.04.2020

Accepted after revision: 21.04.2020

Published online: 15.05 .2020

DOI: 10.1055/s-0040-1707112; Art ID: st-2020-d0183-I

\begin{abstract}
Benzimidazoles represent common chemical moieties in bioactive compounds. The synthesis of this heterocycle often involves a condensation of an ortho-phenylenediamine with a carboxylic acid derivative. The observed dialkylation of the starting ortho-phenylenediamine is avoided by opening of lactones or lactams. This strategy can directly yield $1 \mathrm{H}$-benzimidazoles substituted at the 2 -position by a functionalized chain. We present herein a study of the effect of different electron-withdrawing or electron-donating groups at the 4-position of ortho-phenylenediamines on the opening of lactones or lactams to synthesize benzimidazol-2-yl alkanols and benzimidazol-2-yl alkylamines.
\end{abstract}

Key words 2-benzimidazol-2-yl alkanols, 2-benzimidazol-2-yl alkylamines, ortho-phenylenediamines, lactones, lactams

Benzimidazoles represent a common chemical moiety in bioactive compounds such as antimicrobials, food preservatives, antiulcer, antiviral and anti-cancer agents (Figure 1). ${ }^{1-3}$ The synthesis of this heterocycle often involves condensation of an ortho-phenylenediamine with a carbonyl derivative (Scheme 1$)^{4,5}$ and, most recently, with orthoesters. ${ }^{6}$ The dialkylation of the starting ortho-phenylenediamine with a carboxylic acid, aldehyde, acid anhydride, acid chloride, or nitrile (Scheme 1, path A), can be avoided by ring-opening of lactones or lactams under acidic conditions (Scheme 1, path B). ${ }^{7-14}$ Advantageously, path B directly yields $1 H$-benzimidazoles substituted at the 2 -position by a functionalized chain and these are of particular interest in synthesis. In fact, as part of the synthesis of a bioactive chemical library in our team, we used this efficient path- way to afford different benzimidazol-2-yl alkanols and benzimidazol-2-yl alkylamines as synthetic stating materials. We focused on exploring the effect of different substituents at the 4-position of the monosubstituted ortho-phenylenediamine in the reaction with different lactones or lactams.

2 -Substituted $1 \mathrm{H}$-benzimidazoles with a side chain containing either a hydroxyl group or a primary amine were obtained by a one-pot reaction under acidic conditions of ortho-phenylenediamine with a lactone or a lactam, respectively. One equivalent of 4-(tert-butyl)benzene-1,2-diamine reacts with an excess (4-6 equivalents, adjusted to obtain a full reaction) of a lactone or a lactam in $4 \mathrm{~N} \mathrm{HCl}$ at reflux in a sealed tube during 12-24 hours or until disappearance of the limiting reagent monitored by TLC (experimental conditions A). ${ }^{15}$ This reaction was initially explored with lactones and lactams of different size (Table 1 ). The benzimidazol-2-yl alkanols were obtained in very good yields (69-

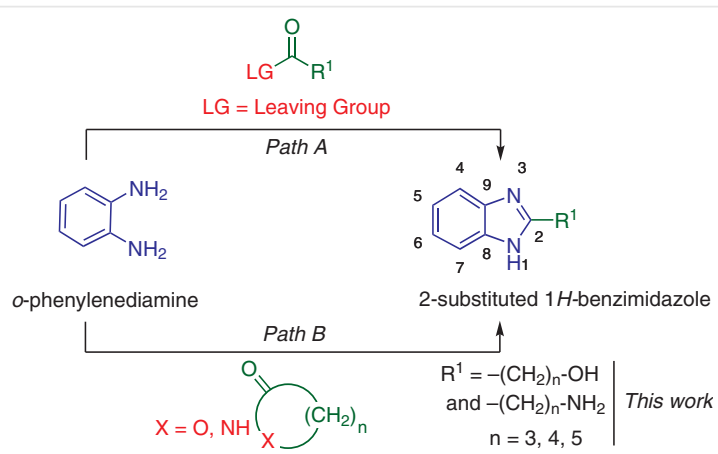

Scheme 1 Principal synthetic pathways to obtain $1 \mathrm{H}$-benzimidazoles 

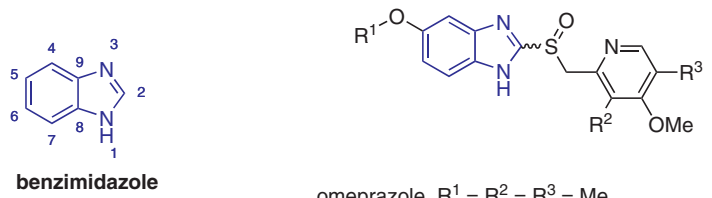

omeprazole, $R^{1}=R^{2}=R^{3}=M e$ pantoprazole, $\mathrm{R}^{1}=\mathrm{CHF}_{2}, \mathrm{R}^{2}=\mathrm{OMe}, \mathrm{R}^{3}=\mathrm{H}$ proton pump inhibitors

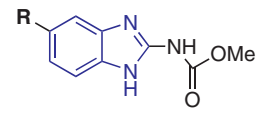
albendazole, $\mathrm{R}=\mathrm{S}-\mathrm{CH}_{2}-\mathrm{CH}_{2}-\mathrm{CH}_{3}$ mebendazole, $\mathrm{R}=\mathrm{COPh}$ antiparasitic agents<smiles>c1ccc2[nH]c(-c3cscn3)nc2c1</smiles>
EtO

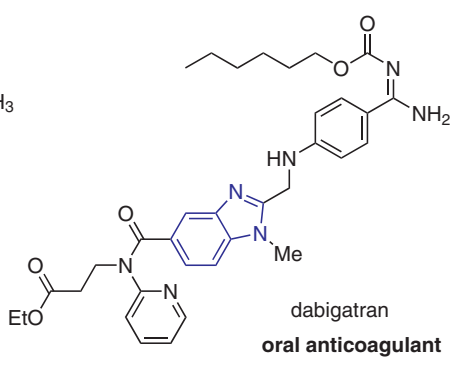

tiabendazole antifungal food preservative<smiles>CC(C)N(C[C@H](O)C(O)(O)n1cnc2c(N)ncnc21)C1CC(CCc2nc3cc(C(C)(C)C)ccc3[nH]2)C1</smiles>

anticancer agents

Figure 1 Examples of benzimidazole-containing bioactive compounds

93\%). The reaction yield with $\gamma$-butyrolactone (entry 1 ) was slightly better than those obtained with higher homologues (entries 2 and 3). The benzimidazol-2-yl alkylamines were obtained in lower yields, from 9 to 49\% (entries 4-6). Use of $\gamma$-butyrolactam seems to adversely affect the yield of $\mathbf{2 a}$, possibly due to the relatively poor stability of the starting five-membered lactam.

Experimental conditions A were then applied to explore the impact on the reaction of donating groups $(t-\mathrm{Bu}, \mathrm{Me}$, $\mathrm{OMe}, \mathrm{OH})$ and withdrawing groups $\left(\mathrm{Cl}, \mathrm{CF}_{3}, \mathrm{NO}_{2}, \mathrm{CN}\right)$ at the 4-position of the ortho-phenylenediamine. The six-membered lactone ( $\delta$-valerolactone) and lactam ( $\delta$-valerolactam), the most stable rings, were chosen to examine the scope of the synthesis of benzimidazol-2-yl alkanols and benzimidazol-2-yl alkylamines (Table 2). We observed that the isolated yield of the reaction was higher in the presence of both types of substituents compared to that obtained using unsubstituted ortho-phenylenediamine (entries 1 and $6)$, except for 4-chlorobenzene-1,2-diamine (entry 13). This positive effect of the substituents on the yield has also been observed at the 3-position of monosubstituted orthophenylenediamines. ${ }^{16}$ Furthermore, we observed that the overall average time of reaction was shortened in the presence of electron-donating groups (EDG). In fact, all electron-donating substituents at the para-position positively affect the reactivity of the $\mathrm{NH}_{2}$ (Scheme 2). ${ }^{17-20}$ Electronwithdrawing groups (EWG) reduce the nucleophilicity of the para- $\mathrm{NH}_{2}$ without affecting the nucleophilicity of the meta- $\mathrm{NH}_{2}$, while electron-donating groups (EDG) increase the nucleophilicity of the para- $\mathrm{NH}_{2}$ without affecting the nucleophilicity of the meta- $\mathrm{NH}_{2}$. In both cases, the carbonyl of the lactone (or lactam) is first attacked by the more activated of the two amino groups of the ortho-phenylenediamine, followed by the attack of the other amino group. Although the order of attack is not relevant for the regiochemical outcome of the reaction, due to tautomerism of the resulting benzimidazole the presence of electron-donating groups appears to increase the rate of reaction (Scheme 2C). 4-Chlorobenzene-1,2-diamine shows a reactivity pattern similar to that of the non-substituted orthophenylenediamine, explained by the well-known simultaneous withdrawing and donating effect of the chlorine atom, common to the other halides.

Further benzimidazol-2-yl alkylamines were also synthesized via a three-step synthesis pathway. Thus, the corresponding benzimidazol-2-yl alkanol (1 equiv) previously obtained under conditions A was engaged in a Mitsunobu reaction with phthalimide ( 2 equiv) in the presence of diisopropyl azodicarboxylate (DIAD, 2 equiv) and triphenylphosphine ( 2 equiv) in diethyl ether over 12-20 hours at room temperature. The phthalimido-derivative thus obtained subsequently reacts with hydrazine monohydrate (12 equiv) in ethanol over 12 hours at room temperature to release the corresponding primary amine (experimental conditions B) (Table 3). ${ }^{21}$ Diethyl ether was preferred over THF for the Mitsunobu reaction in order to favor the precipitation and removal of triphenylphosphine oxide $\left(\mathrm{Ph}_{3} \mathrm{PO}\right)$ and to facilitate the isolation of the phthalimido derivative. In spite of these precautions, the yield of this step remained low. Thus, the non-isolated phthalimido-derivatives were directly treated with hydrazine monohydrate, improving the overall yield. Nevertheless, the desired benzimidazol-2-

Table 1 Synthesis of 2 -Substituted $1 \mathrm{H}$-Benzimidazoles via the Opening of Lactones and Lactams

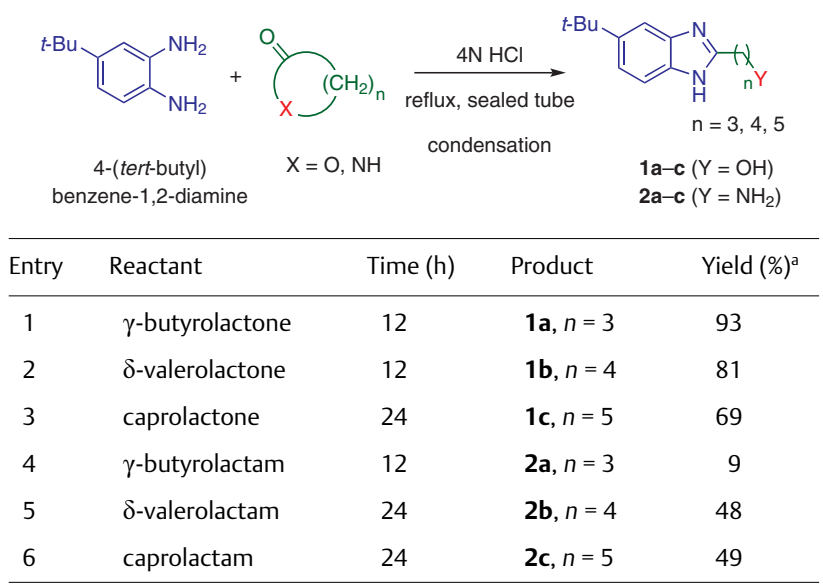

a Isolated yield. 
A. Impact of an electron-withdrawing group (EWG) on the nucleophilicity of the $p-\mathrm{NH}_{2}$
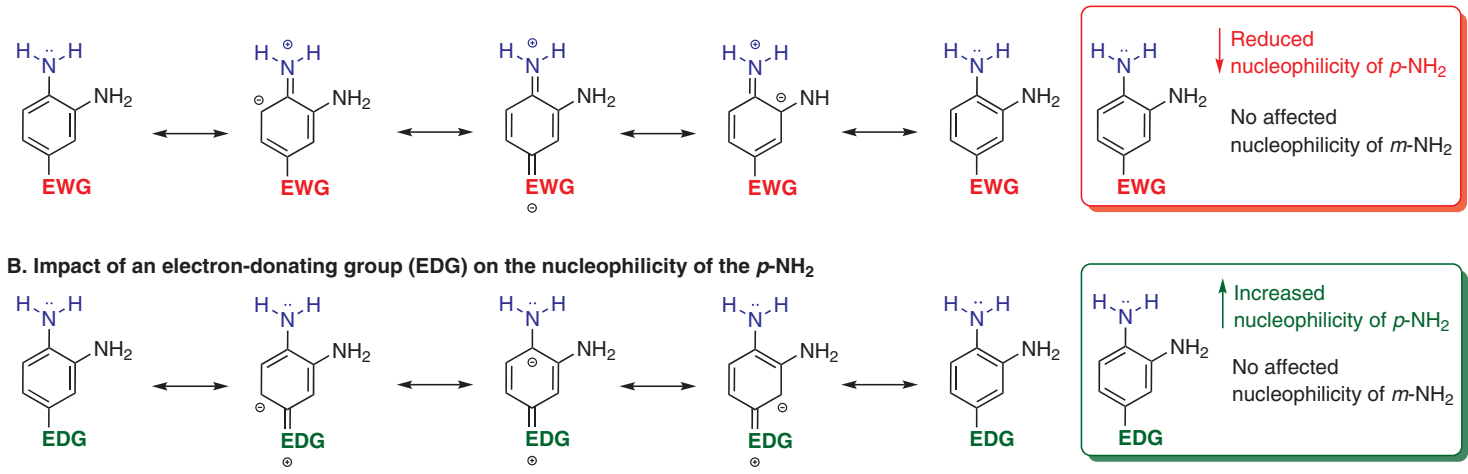

C. Formation of the benzimidazole showing its tautomeric forms

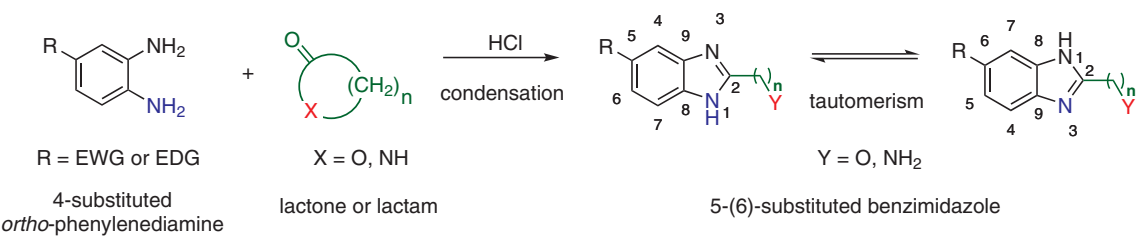

Scheme 2 Impact of mono-substitution of ortho-phenylenediamine on its nucleophilicity

Table 2 Synthesis of Benzimidazol-2-yl Alkanols and Benzimidazol-2-yl Alkylamines

\begin{tabular}{|c|c|c|c|c|}
\hline \multicolumn{2}{|c|}{$o$-phenylenediamine } & \multicolumn{2}{|c|}{$\begin{array}{l}\delta \text {-valerolactone }(\mathrm{X}=\mathrm{O}) \\
\delta \text {-valerolactam }(\mathrm{X}=\mathrm{NH})\end{array}$} & \multirow{2}{*}{$\begin{array}{r}\mathbf{1} \mathbf{b}, \mathbf{d}-\mathbf{g}(\mathrm{Y}=\mathrm{OH}) \\
\mathbf{2 b}, \mathbf{d}-\mathbf{k}\left(\mathrm{Y}=\mathrm{NH}_{2}\right) \\
\text { Yield (\%) }\end{array}$} \\
\hline Entry & $\mathrm{R}$ & Time (h) & Product & \\
\hline 1 & $\mathrm{H}$ & 16 & $1 \mathrm{~d}$ & 59 \\
\hline 2 & $t-B u$ & 18 & 1b & 81 \\
\hline 3 & OMe & 12 & $1 e$ & 91 \\
\hline 4 & $\mathrm{CF}_{3}$ & 16 & $1 f$ & 68 \\
\hline 5 & $\mathrm{NO}_{2}$ & 16 & $1 \mathrm{~g}$ & 76 \\
\hline 6 & $\mathrm{H}$ & 18 & $2 d$ & 30 \\
\hline 7 & $t-\mathrm{Bu}$ & 24 & $2 b$ & 48 \\
\hline 8 & OMe & 12 & $2 e$ & 73 \\
\hline 9 & $\mathrm{CF}_{3}$ & 48 & $2 f$ & 54 \\
\hline 10 & $\mathrm{NO}_{2}$ & 40 & $2 g$ & 81 \\
\hline 11 & Me & 48 & $2 \mathrm{~h}$ & 91 \\
\hline 12 & $\mathrm{OH}$ & 48 & $2 \mathbf{i}$ & 87 \\
\hline 13 & $\mathrm{Cl}$ & 7 & $2 \mathrm{j}$ & 44 \\
\hline 14 & $\mathrm{CN}$ & 20 & $2 k$ & 90 \\
\hline
\end{tabular}

yl alkylamines were obtained in lower yields compared to the one-step synthesis pathway summarized in Tables 1 and 2 (except for Table 3, entry 1 ), mainly due to the formation of a side product during the Mitsunobu reaction. 1,2,3,4-Tetrahydro-pyrido[1.2,a]benzimidazole derivatives 3 were observed (Table 3, entries $4,6,7$ ) as the main products of this reaction. ${ }^{6,16}$ This might be the result of an intramolecular reaction of the phosphonium intermediate, as shown in Scheme 3. ${ }^{22}$ This synthetic pathway could represent an efficient method of synthesis of these heterocyclic compounds.

In summary, a range of benzimidazol-2-yl alkylalkanols and benzimidazol-2-yl alkylamines were prepared in a onestep synthesis between an ortho-phenylenediamine and a lactone or a lactam, respectively, in yields ranging from 44 to $90 \%$. The presence of electron-withdrawing or electrondonating substituents increased the yield of the reaction, compared to the yield obtained when no substituent or a group with a positive inductive effect and a negative mesomeric effect such as chlorine was present. The formation of benzimidazol-2-yl alkylamines via the lactam opening was compared to a three-step synthetic pathway, involving a Mitsunobu reaction on a benzimidazol-2-yl alkanol followed by hydrazine treatment of the obtained phthalimido derivative, which showed very low yields. This confirms the appeal of this straightforward, efficient one-step formation of 2-substituted- $1 \mathrm{H}$-benzimidazole derivatives through lactone or lactam opening. 
Table 3 Benzimidazol-2-yl Alkylamines Obtained by a Three-Step Synthetic Pathway

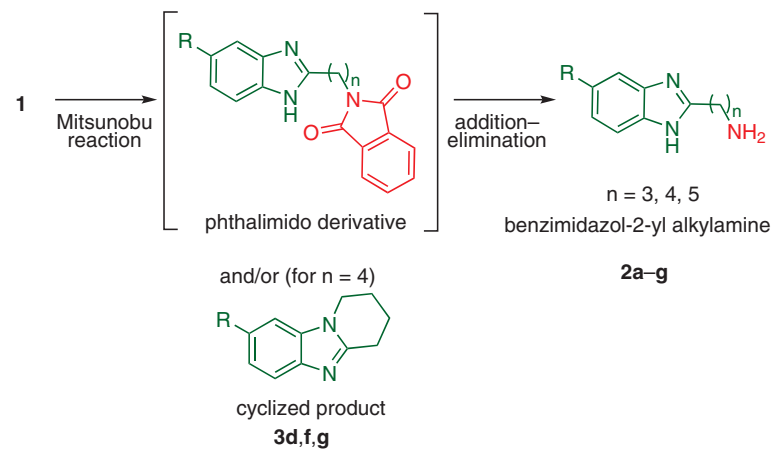

\begin{tabular}{llllll}
\hline Entry & $\mathrm{R}$ & $n$ & $\begin{array}{l}\text { Cyclizedproduct } \\
\text { (yield, \%) }\end{array}$ & Product & $\begin{array}{c}\text { Three-step } \\
\text { yield }(\%)^{\mathrm{b}}\end{array}$ \\
\hline 1 & $t-\mathrm{Bu}$ & 3 & $-^{\mathrm{a}}$ & $\mathbf{2 a}$ & 20 \\
2 & $t-\mathrm{Bu}$ & 4 & $-^{\mathrm{a}}$ & $\mathbf{2 b}$ & 35 \\
3 & $t-\mathrm{Bu}$ & 5 & $-^{\mathrm{a}}$ & $\mathbf{2 c}$ & 14 \\
4 & $\mathrm{H}$ & 4 & $\mathbf{3 d}(66)^{\mathrm{c}, \mathrm{d}}$ & $\mathbf{2 d}$ & 0 \\
5 & $\mathrm{OMe}$ & 4 & $-^{\mathrm{a}}$ & $\mathbf{2 e}$ & 27 \\
6 & $\mathrm{CF}_{3}$ & 4 & $\mathbf{3 f}(42)^{\mathrm{c}}$ & $\mathbf{2 f}$ & 3 \\
7 & $\mathrm{NO}_{2}$ & 4 & $\mathbf{3 g}(51)^{\mathrm{b}}$ & $\mathbf{2 g}$ & 0 \\
\hline
\end{tabular}

${ }^{\mathrm{a}}$ Not observed by LC-MS.

${ }^{b}$ Isolated yield.

'Calculated from the crude material by LC-MS.

${ }^{\mathrm{d}}$ Characterized by NMR.

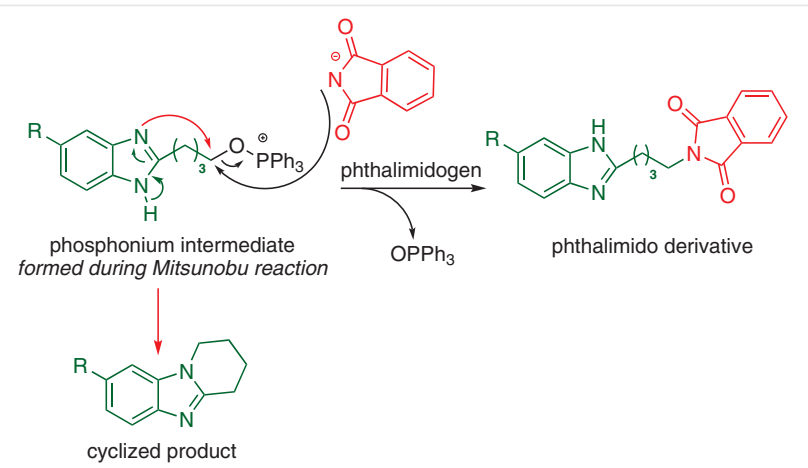

Scheme 3 Formation of a cyclized product in the Mitsunobu reaction

\section{Funding Information}

This work was supported by the Centre National de la Recherche Scientifique (CNRS) and PlanCancer 2014 ( ${ }^{\circ}$ EPIG201401) (to P.B.A), and by a PhD fellowship by the Ecole Doctorale Biologie Santé de Lille (EDBSL, France) National Council of Science and Technology (Consejo Nacional de Ciencia y Tecnología; CONACYT, Mexico) (to O.C.A.).

\section{Acknowledgment}

We thank the PSM GRITA (Plateau Spectrométrie de Masse, Univ Lille) for mass spectrometric analyses. The authors declare no conflict of interest.

\section{Supporting Information}

Supporting information for this article is available online at https://doi.org/10.1055/s-0040-1707112.

\section{References and Notes}

(1) Pullagura, M. K. P.; Avdhut, K. S.; Raja, S. Int. J. Pharm. Pharmaceut. Sci. 2016, 8, 22.

(2) Keri, R. S.; Hiremathad, A.; Budagumpi, S.; Nagaraja, B. M. Chem. Biol. Drug Design 2015, 86, 19.

(3) Srestha, N.; Banerjee, J.; Srivastava, S. IOSR J. Pharm. 2014, 4, 28.

(4) Elshihawy, H.; Helal, M. A.; Said, M.; Hammad, M. A. Bioorg. Med. Chem. 2014, 22, 550.

(5) Alaqeel, S. I. J. Saudi Chem. Soc. 2017, 21, 229.

(6) Bastug, G.; Eviolitte, C.; Markó, I. E. Org. Lett. 2012, 14, 3502.

(7) Reppe, W. Justus Liebigs Ann. Chem. 1955, 1208.

(8) Botta, A. Justus Liebigs Ann. Chem. 1976, 336.

(9) Olhava, E. J.; Chesworth, R.; Kuntz, K. WO/2012/075492, 2012.

(10) Keurulainen, L.; Vahermo, M.; Puente-Felipe, M.; SandovalIzquierdo, E.; Crespo-Fernández, B.; Guijarro-López, L.; HuertasValentín, L.; de las Heras-Dueña, L.; Leino, T. O.; Siiskonen, A.; Ballell-Pages, L.; Sanz, L. M.; Castañeda-Casado, P.; JiménezDíaz, M. B.; Martínez-Martínez, M. S.; Viera, S.; Kiuru, P.; Calderón, F.; Yli-Kauhaluoma, J. J. Med. Chem. 2015, 58, 4573.

(11) Shelton, K. L.; DeBord, M. A.; Wagers, P. O.; Southerland, M. R.; Williams, T. M.; Robishaw, N. K.; Shriver, L. P.; Tessier, C. A.; Panzner, M. J.; Youngs, W. J. Bioorg. Med. Chem. 2017, 25, 421.

(12) Indusegaram, S.; Katsifis, A. G.; Ridley, D. D.; Vonwiller, S. C. Aust. J. Chem. 2003, 56, 819.

(13) Woudenberg, R. C.; Coughlin, E. B. Tetrahedron Lett. 2005, 46, 6311.

(14) Lee, J. E.; Kwon, T. H.; Gu, S. J.; Lee, D.-H.; Kim, B. M.; Lee, J. Y.; Lee, J. K.; Seo, S. H.; Pae, A. N.; Keum, G.; Cho, Y. S.; Min, S.-J. Org. Biomol. Chem. 2014, 12, 5669.

(15) General Conditions A: A mixture of the corresponding orthophenylenediamine ( 1 equiv) and the corresponding lactone or lactam (4-6 equiv) in $4 \mathrm{~N} \mathrm{HCl}$ in a sealed tube was heated overnight (duration is reported in the manuscript). After cooling to room temperature, the $\mathrm{pH}$ was adjusted to $\mathrm{pH} 11$ at $0{ }^{\circ} \mathrm{C}$ with sat. aq. $\mathrm{K}_{2} \mathrm{CO}_{3}$. The aqueous layer was extracted three times with EtOAc, the combined organic layers were washed with brine, dried over $\mathrm{MgSO}_{4}$, filtered, and concentrated in vacuo. The desired product was obtained by precipitation or by chromatography on silica gel [eluting with $\mathrm{CH}_{2} \mathrm{Cl}_{2}-\mathrm{MeOH} / \mathrm{ammonia}$, 9:1 $(\mathrm{v} / \mathrm{v})]$. The final solid or oil obtained was dried over $\mathrm{P}_{2} \mathrm{O}_{5}$.

Representative example 1a: Yield: $4.3 \mathrm{mmol}$ (93\%); white powder obtained from diethyl ether; mp $181-183{ }^{\circ} \mathrm{C} .{ }^{1} \mathrm{H}$ NMR (300 MHz, DMSO- $\left.d_{6}\right): \delta=1.33(\mathrm{~s}, 9 \mathrm{H}, t-\mathrm{Bu}), 1.90\left(\mathrm{tt},{ }^{3} J=6.0\right.$, $\left.7.5 \mathrm{~Hz}, 2 \mathrm{H}, \mathrm{CH}_{2}\right), 2.83\left(\mathrm{t},{ }^{3} \mathrm{~J}=7.5 \mathrm{~Hz}, 2 \mathrm{H}, \mathrm{CH}_{2}-\mathrm{Ar}\right), 3.49\left(\mathrm{t},{ }^{3} \mathrm{~J}=\right.$ $\left.6.0 \mathrm{~Hz}, 2 \mathrm{H}, \mathrm{CH}_{2}-\mathrm{OH}\right), 7.17-7.20(\mathrm{~m}, 1 \mathrm{H}, \mathrm{ArH}), 7.35-7.40(\mathrm{~m}$, $2 \mathrm{H}, \mathrm{ArH}), 11.86$ (br s, $1 \mathrm{H}, \mathrm{NH}) .{ }^{13} \mathrm{C}$ NMR (75 MHz, DMSO-d ${ }_{6}$ ): $\delta=25.3\left(\mathrm{CH}_{2}\right), 30.8\left(\mathrm{CH}_{2}\right), 31.7(t-\mathrm{Bu}), 34.3(\mathrm{Cq}), 60.2\left(\mathrm{CH}_{2}-\mathrm{OH}\right)$, 
118.8 (3 CHAr), 143.8 (Cq), 154.9 (Cq). HRMS (ESI $\left.{ }^{+}\right): m / z[M+$ $\mathrm{H}]^{+}$calcd for $\mathrm{C}_{14} \mathrm{H}_{21} \mathrm{~N}_{2} \mathrm{O}$ : 233.1648; found: 233.1648. IR: 3117 $(\mathrm{OH}) \mathrm{cm}^{-1}$.

(16) Rezaul Haque, M.; Rasmussen, M. Tetrahedron 1997, 53, 6937.

(17) Venkatasubramanian, N.; Sabesan, A. Can. J. Chem. 1969, 47, 3710.

(18) Shazhenov, A. A.; Kadyrov, C. S.; Kurbanov, P. Chem. Heterocycl. Compd. 1972, 8, 580.

(19) Hoefnagel, A. J.; Hoefnagel, M. A.; Wepster, B. M. J. Am. Chem. Soc. 1976, 98, 6194.

(20) Gross, K. C.; Seybold, P. G. Int. J. Quantum Chem. 2000, 80, 1107.

(21) General Conditions B: Triphenylphosphine (2 equiv, $4.5 \mathrm{~g}, 17.1$ $\mathrm{mmol}$ ) was added in portions to a solution of $\mathbf{1 a}$ (1 equiv, $2 \mathrm{~g}$, $8.6 \mathrm{mmol}$ ), phthalimide (2 equiv, $2.5 \mathrm{~g}, 17.1 \mathrm{mmol}$ ) and DIAD (2 equiv, $3.4 \mathrm{~mL}, 17.1 \mathrm{mmol}$ ) in diethyl ether $(40 \mathrm{~mL})$, and the mixture was stirred overnight at room temperature. The triphenylphosphine oxide precipitate was removed by filtration, and the filtrate was concentrated in vacuo. Diethyl ether was added to the residue and the additional precipitate was also removed by filtration. The filtrate was concentrated in vacuo, then ethanol $(20 \mathrm{~mL})$ and hydrazine monohydrate (12 equiv, $5 \mathrm{~mL}$, $103 \mathrm{mmol}$ ) were added to the viscous residue. After heating at reflux overnight, the reaction mixture was cooled to room temperature and the solid phthalhydrazide was removed by filtra- tion. The filtrate was concentrated in vacuo, and ethanol was added to the residue. The precipitate was again removed by filtration, the filtrate was concentrated in vacuo and the residue was purified by column chromatography over silica gel [eluting with $\left.\mathrm{CH}_{2} \mathrm{Cl}_{2}-\mathrm{CH}_{3} \mathrm{OH} / \mathrm{ammonia}, 9: 1(\mathrm{v} / \mathrm{v})\right]$. The oil obtained was dried over $\mathrm{P}_{2} \mathrm{O}_{5}$.

2-(3-(5-(tert-Butyl)-1H-benzo[d]imidazol-2-yl)propyl)isoindoline-1,3-dione (4): Yellowish powder. ${ }^{1} \mathrm{H}$ NMR $(300 \mathrm{MHz}$, DMSO- $d_{6}$ ): $\delta=1.30(\mathrm{~s}, 9 \mathrm{H}, t-\mathrm{Bu}), 2.09\left(\mathrm{tt},{ }^{3} J=6.8,7.1 \mathrm{~Hz}, 2 \mathrm{H}\right.$, $\left.\mathrm{CH}_{2}\right), 2.82\left(\mathrm{t},{ }^{3} \mathrm{~J}=7.1 \mathrm{~Hz}, 2 \mathrm{H}, \mathrm{CH}_{2}-\mathrm{Ar}\right), 3.67\left(\mathrm{t},{ }^{3} \mathrm{~J}=6.8 \mathrm{~Hz}, 2 \mathrm{H}\right.$, $\left.\mathrm{CH}_{2}-\mathrm{N}\right), 7.13(\mathrm{~m}, 1 \mathrm{H}, \mathrm{ArH}), 7.31(\mathrm{~m}, 2 \mathrm{H}, \mathrm{ArH}), 7.82(\mathrm{br} \mathrm{s}, 4 \mathrm{H}$, ArH), 11.97 (s, $1 \mathrm{H}, \mathrm{NH})$. IR: $1705(\mathrm{C}=\mathrm{O}) \mathrm{cm}^{-1}$.

3-(5-(tert-Butyl)-1H-benzo[d]imidazol-2-yl)propan-1-amine (2a): Yield: $0.4 \mathrm{mmol}$ (overall yield $20 \%$ ); brown oil. ${ }^{1} \mathrm{H}$ NMR $\left(300 \mathrm{MHz}, \mathrm{DMSO}-d_{6}\right): \delta=1.32(\mathrm{~m}, 9 \mathrm{H}, t-\mathrm{Bu}), 1.80\left(\mathrm{tt},{ }^{3} \mathrm{~J}=6.9\right.$, 7.6, $\left.2 \mathrm{H}, \mathrm{CH}_{2}\right), 2.66\left(\mathrm{t},{ }^{3} \mathrm{~J}=6.9 \mathrm{~Hz}, 2 \mathrm{H}, \mathrm{CH}_{2}-\mathrm{NH}_{2}\right), 2.82\left(\mathrm{t},{ }^{3} \mathrm{~J}=\right.$ $\left.7.6 \mathrm{~Hz}, 2 \mathrm{H}, \mathrm{CH}_{2}-\mathrm{Ar}\right), 3.16\left(\mathrm{~m}, 2 \mathrm{H}, \mathrm{NH}_{2}\right), 7.18\left(\mathrm{dd},{ }^{3} \mathrm{~J}=8.4 \mathrm{~Hz},{ }^{4} \mathrm{~J}=\right.$ $1.6 \mathrm{~Hz}, 1 \mathrm{H}, \mathrm{ArH}), 7.34\left(\mathrm{~d},{ }^{3} J=8.4,1 \mathrm{H}, \mathrm{ArH}\right), 7.38\left(\mathrm{~d},{ }^{4} J=1.6 \mathrm{~Hz}\right.$, $1 \mathrm{H}, \mathrm{ArH}) .{ }^{13} \mathrm{C}$ NMR $\left(75 \mathrm{MHz}\right.$, DMSO- $\left.d_{6}\right): \delta=26.0\left(\mathrm{CH}_{2}\right), 30.5$ $\left(\mathrm{CH}_{2}\right), 31.7(t-\mathrm{Bu}), 34.3(\mathrm{Cq}), 40.7\left(\mathrm{CH}_{2}-\mathrm{NH}_{2}\right), 118.8$ (3 CHAr), 143.9 (Cq), $160.7(\mathrm{Cq})$. HRMS $\left(\mathrm{ESI}^{+}\right): \mathrm{m} / z[\mathrm{M}+\mathrm{H}]^{+}$calculated for $\mathrm{C}_{14} \mathrm{H}_{22} \mathrm{~N}_{3}$ : 232.1808; found: 232.1801. IR: $3041(\mathrm{NH}) \mathrm{cm}^{-1}$.

(22) Wright, J. B. Chem. Rev. 1951, 48, 397. 